\title{
The Irkutsk Transportation Master Plan solutions for public transport system development
}

\author{
M. Sharov, A. Levashev \& A. Mikhailov \\ Transportation Laboratory, Irkutsk State Technical University, Russia
}

\begin{abstract}
Irkutsk has extremely favourable conditions for developing the electric public transportation system. The basis of the regional power system is the Irkutsk hydropower station. It has a unique feature; the stability of seasonal power production throughout the year. Due to this factor, the cost of power production in Irkutsk is one of the lowest in the world.

The master plan for Irkutsk was created in 1985 and was intended as a means to further the development of the tram network. However, ten years later, the tramline was excluded from the technical project of the new bridge across Angara River. As a result, private bus companies received the most lucrative segment of the public transport system and the municipal network of electric public transport became ineffective and received a negative economic balance.

In 2008-2010 the transportation laboratory of Irkutsk State Technical University (TL ISTU) created the Transportation Master Plan for Irkutsk. The goal of this project was to forecast traffic and passenger flow distribution up to 2020 .

According to TL ISTU forecasts, the largest daily passenger and traffic flows are between the Sverdlovsky borough and the city center. TL ISTU has modelled several combinations of routes for the public transport system, including the consideration of a new bridge over the Angara River and arguing for the municipal trolleybus network development.

Keywords: public transport, transportation demand estimation, transport master plan, transport and passenger flows, macrosimulation.
\end{abstract}

\section{Introduction}

Urban transport is one of the main energy consumers in the cities as well as being one of the main sources of urban air pollution. 
According to some experts [1] the cities can be divided into three groups depending on their share in energy consumption. In the cities of economically developed countries the largest share of energy consumption is heating and electric supply of residential and business buildings. The second biggest energy consuming areas are transportation and industries. In cities such as London, Bologna and Tokyo $25-38 \%$ of energy is consumed by the transportation sector. However, in cities like Mexico City, Hong Kong, and Cape Town, where the level of economic development is termed as average, transportation consumes up to $50-56 \%$ of all energy. In the case of the cities of South-Eastern Asia, this share is usually $5-8 \%$.

Despite the energy consumption caused by long cold winters, Irkutsk belongs to the second type cities, as defined in the above. Its highway network is not developed enough and causes recurrent transport congestion.

Internationally, organisations such as the United Nations Environment Programme and the UITP European Union Committee have developed concepts of the 'sustainable city', the 'resource efficient city', the 'energy efficient city' and the 'smart city', which are intended to solve the environmental problems of modern cities and agglomerations [2, 3]. 'Smart greed' and 'smart transportation' are listed as the main characteristics of the concepts mentioned above. The first characteristic is aimed towards rational energy distribution. The second one is proposed to reduce the energy and oil consumption of urban transport. The most effective tool to solve this problem is the priority of public transport development (or transit oriented development).

In the Russian Federation the scientific community and society have begun to discuss the issue of the energy efficiency of urban transportation systems $[1,4,5]$.

\section{The model of the Irkutsk transportation system}

Irkutsk Municipal Administration suggested to the TL ISTU to create a new concept of public transport development. TL ISTU has considered it in terms of sustainable city and smart city concepts. The stages of this project were as follows:

- The estimation of current transportation demand.

- The estimation of future transportation demand, passenger and transport flow distribution in 2020 .

- The estimation of the current network of public passenger transport.

- The proposals on the public passenger network development.

The model of the Irkutsk transportation system was developed using the VISUM package and includes the urban highway network and the public transport routes network. Both networks contain 96 transportation analysis zones (which make 19 aggregated zones), 10778 links, 4246 nodes, and 372 public transport stops. The Irkutsk's model is considered as a part of the regional transport model and will be further transferred into the model of Irkutsk agglomeration. 
In order to estimate current transportation demand 6000 people were interviewed about their daily mobility. The detailed interviewing is including questions about daily number of trips, origins and destinations of trips, modes and purposes of trips, trips duration and share of time spending (excess, weighting, riding, the route changing etc.).

\section{Current transportation demand}

The data for the current transportation demand has shown that trips are very unevenly distributed (Figure 1).

The largest number of trips is generated between the Sverdlovskiy and Oktyabrskiy boroughs (347,500 trips per day in both directions), while the largest number of trips is generated within the Oktyabrskiy borough (335,000 trips per day).

This spatial distribution has an exact explanation. About 190,000 people, almost one third of the city population, live in the Sverdlovskiy borough, which is located on the left Angara River bank. However, a significant number of jobs and several universities are situated on the right bank. As a result, a strong commuting effect is observed, i.e. the convincing preponderance of trips from the left bank to the right in the morning peak period and respectively the reverse phenomenon in the evening.

The commerce and tertiary sector concentration in the historical city center also produces an additional effect on the trips' spatial distribution. Since 1990 the 'Inner Core' has been formed in the center of Irkutsk and precisely took the place of previous 19th century markets. Its area is about 40 ha and approximately $300,000 \mathrm{~m}^{2}$ of commerce floor area is located there. The concentration and mixture of activities in this Inner Core causes the attraction of the urban, suburban and regional population and thus, firms and companies prefer to locate new activities within this spot. So, the fact that traffic and pedestrian volumes increase is a stable trend of this territory. The results of our current mobility research showed that approximately $50 \%$ of all shopping trips are located in the city historical center.

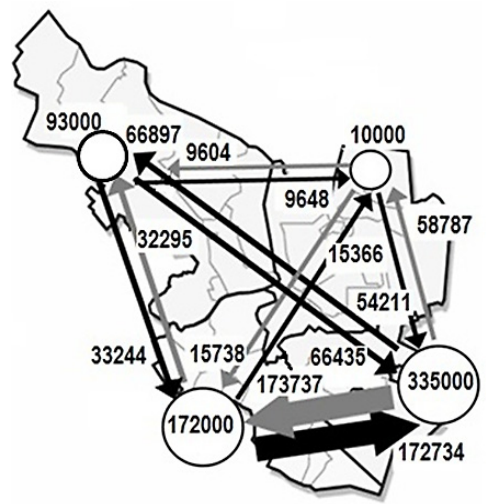

Figure 1: $\quad$ Travel demand (number of trips per day) distribution between and within four boroughs of Irkutsk. 


\section{Forecasts of transport and passenger flows distribution}

Origin-destination matrices estimations and the passenger and transport flow distribution forecasts were made up to the year of 2020. The values mentioned below were used in the calculations and forecasts:

- $\quad$ city total population: 620,000 ;

- $\quad$ vehicle-to-population ratio: 0.3 vehicles per capita;

- $\quad$ population mobility growth: by $10 \%$;

- $\quad$ average car occupancy: 1.3 people per car.

Statistical data and the gravity function are taken from the mobility research data of 2006-2008. The distributions of passenger and transport flows were modeled using the VISUM package and the following scenarios of the Irkutsk highway network development are considered:

1. existing highway network remains unchanged;

2. construction of the 4 th bridge (no ring road);

3. construction of the ring freeway;

4. construction of the ring freeway and the 4th bridge.

Ideally, the urban highway network should correspond to the minimal total mileage:

$$
\min \sum_{i=1}^{n} v_{i} \cdot l_{i}
$$

$v_{i}=$ traffic volumes on the network graph link, $i ; l_{i}=$ link length $i$.

The estimate (1) can be interpreted as the optimal solution in terms of fuel consumption and emission because it can be easily transformed into another estimate:

$$
\min \left(C \cdot \sum_{i=1}^{n} v_{i} \cdot l_{i}\right)
$$

$C=$ fuel consumption per 1 kilometer.

The estimate (1) was calculated for each scenario of the highway network development, using the VISUM package and values of $v_{i}$ and $l_{i}$ extracted from the Irkutsk transportation model. Data analysis shows that the best scenario is the fourth one, which suggests construction of the ring freeway and new fourth bridge (Table 1).

Table 1: Vehicle mileage depending on scenarios of highway network development.

\begin{tabular}{|c|l|c|}
\hline Scenario & Scenario features & $\begin{array}{l}\text { Daily mileage, } \\
\text { thousands of } \\
\text { kilometers }\end{array}$ \\
\hline 1 & $\begin{array}{l}\text { existing highway network remains } \\
\text { unchanged }\end{array}$ & 1893 \\
\hline 2 & construction of the 4th bridge & 1858 \\
\hline 3 & construction of the ring freeway & 1884 \\
\hline 4 & $\begin{array}{l}\text { construction of the ring freeway and 4th } \\
\text { bridge }\end{array}$ & 1770 \\
\hline
\end{tabular}




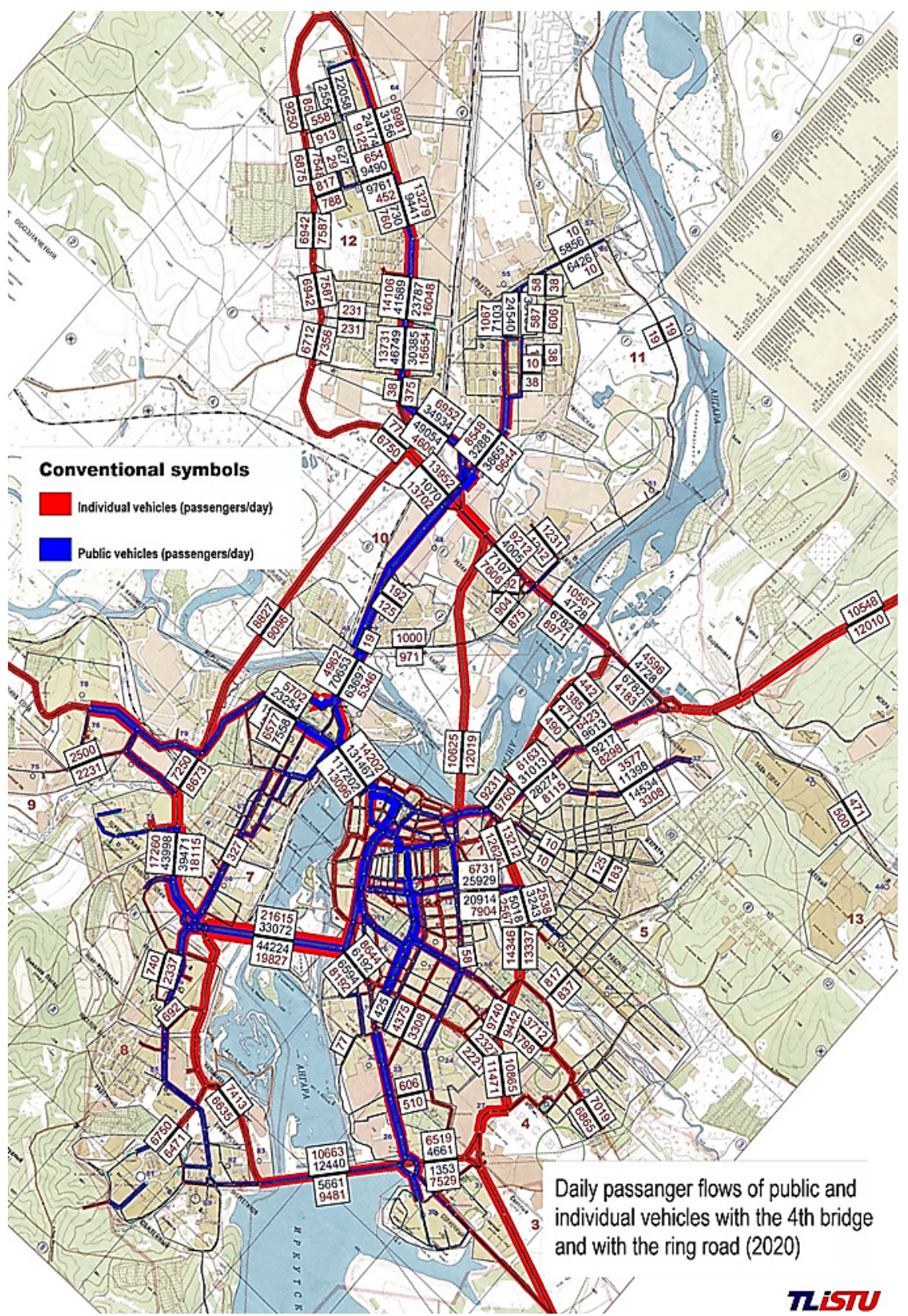

Figure 2: Results of passenger and traffic flow microsimulation. Scenario 4 - distribution of the passenger flows (two modes: public transport and private cars). 
Table 2: Daily traffic volumes on the main Irkutsk's bridges according to scenarios of highway network development.

\begin{tabular}{|l|c|c|c|c|}
\hline \multirow{2}{*}{ River connections } & \multicolumn{4}{|c|}{ Daily traffic volume, cars/day } \\
\cline { 2 - 5 } & \multicolumn{4}{|c|}{ Scenario } \\
\cline { 2 - 5 } & 1 & 2 & 3 & 4 \\
\hline $\begin{array}{l}\text { Hydroelectric power plant } \\
\text { (embankment) }\end{array}$ & 2309 & 2284 & 2476 & 2385 \\
\hline Akademicheskiy Bridge & 5265 & 5085 & 5421 & 5082 \\
\hline Glazkovskiy Bridge & 4492 & 3738 & 4880 & 4217 \\
\hline Nizhniy Angarskiy Bridge & 4494 & 2447 & 3784 & 2286 \\
\hline The bridge over the Irkut River & 4076 & 3141 & 2444 & 1771 \\
\hline
\end{tabular}

The 4th scenario would reduce total daily mileage as well as transport flows to the central part of the city, i.e. over Glazkovskiy Bridge, thus, this scenario was chosen as the basis of the future public transport network development.

\section{Analysis of current public transport network}

The quality of the passenger transportation system is estimated using current and future travel demands and on forecasts of passenger flow distributions.

The first disadvantage of the current network is its low accessibility, which makes public transport less attractive. Current density of the public transport network is only $1.75 \mathrm{~km} / \mathrm{km}^{2}$ in residential areas. In accordance to Russian urban planning standards the minimal network density, which is necessary to organize mass passenger transport, should be $2-2.5 \mathrm{~km} / \mathrm{km}^{2}$.

The bus network containing 86 routes is the most developed. It served by single buses. Private operators control about 920 buses and microbuses total. Most of the high-capacity buses of private operators are old "secondhand" vehicles from South Korea. Private operators serving sufficient passenger flows (for example, route Novolenino district - Downtown has 4,500 passengers during the morning rush hour); therefore, their share is gradually growing. Currently, this share had risen up to a value of $55 \%$.

The Irkutsk municipality manages the electric passenger transport and its infrastructure but the effectiveness of this control is questionable. The Irkutsk master plan, which made in 1985, implied further development of the tram network, which suggested construction of a loop line connecting left and right banks of the river in Irkutsk. Ten years later the tram ring line was excluded from the technical project of the new bridge across Angara River. This decision marked a new municipal policy, which declared that private firms are the most effective and predictably they seized the most lucrative sectors of the transportation network. As a result, maintenance on electric public transport system, owned by municipal government of Irkutsk, became not affective in economic terms at least during last 10 years. 
The current state of the tram network is as follows:

- $\quad$ total tram network length: $23 \mathrm{~km}$;

- $\quad$ summary length of 5 tram routes: $47 \mathrm{~km}$;

- $\quad$ total number of trams (fleet): 58.

Tram route 1 is the most popular, as it connects the city center with the ISTU campus, making it the only profitable route.

Trolleybus network has the following key indicators:

- $\quad$ total trolleybus network length: $25 \mathrm{~km}$;

- $\quad$ summary length of 10 routes: $47 \mathrm{~km}$;

- $\quad$ total number of trolleybuses (fleet): 56.

This scope of trolleybus network and fleet are insufficient for Irkutsk, whose population is 600,000 . For comparison, we show the trolleybus networks characteristics of other cities of Russia (Table 3), which are in much worse conditions in terms of electricity supply and its cost.

Currently trolleybus routes are only touching the periphery of the largest passenger flows formation zone, as a result two thirds of trolleybus routes are inefficient and unprofitable. Thus, the development of the trolleybus route network is suggested as a tool to improve economic indicators of the municipal electric transport system.

Table 3: Trolleybus network of Russian cities with a population of $300,000-500,000$.

\begin{tabular}{|l|l|l|l|}
\hline City & Population & Routs & Vehicles \\
\hline Belgorod & 365000 & 11 & 75 \\
\hline Bryansk & 410000 & 25 & 177 \\
\hline Vladimir & 340000 & 8 & 135 \\
\hline Kirov & 470000 & 8 & 157 \\
\hline Saransk & 325000 & 17 & 141 \\
\hline Stavropol & 412000 & 6 & 96 \\
\hline Tomsk & 525000 & 8 & 93 \\
\hline Tula & 500000 & 10 & 115 \\
\hline Vologda & 310000 & 6 & 90 \\
\hline
\end{tabular}

\section{Public transport network development proposals}

Irkutsk has extremely favourable conditions for developing its electric public transportation system. Today, Irkutsk regional power generation base comprises of various hydro and thermal power plants: 3 hydraulic power plants, 9 thermal power plants and electricity transmission networks [6]. The population of the Irkutsk region is 2.3 million people, while its share of national energy production is $6-8 \%$. So, the regional energy production per capita is one of the highest in the world, similar, for example, to Norway.

Irkutsk has its own power plants. The 50-year-old Irkutsk hydroelectric power plant is the first one on the Angara River as well as in East Siberia. A project of capacity increasing of the Irkutsk hydroelectric power plant made in lust decade 
and in accordance with its proposals, the power production will be increased by $15 \%$. It is one of the reasons explaining Irkutsk has the lowest energy prices in the country: 0.72 roubles per 1 kilowatt [6]. In comparison to Moscow prices, it is 5 times lower, since last year (2013) the price in Moscow grew by up to 4.02 roubles $/ \mathrm{kW}$.

Another feature of Irkutsk is the excessive air pollution. It should be especially noted that $60 \%$ of air pollution in Irkutsk are produced by transport. Microclimate features of the Angara River valley, where Irkutsk is located, also cause the increase of air pollution. The continuous stable anticyclones are prevailing in winter season, so the wind velocities, which is do not exceed 1 meter per second, are typical in winter period. According to the environmental protection criteria it is preferable for Irkutsk to develop electric passenger transport network.

New trolleybus infrastructure is suggested on the Akademicheskiy Bridge, this new "crosspiece" can add several new routes to the current trolleybus network (Figure 3 and 4). The length of the new infrastructure is $3.35 \mathrm{~km}$ and because the average cost of the trolleybus network is 5-7 million rubles per $1 \mathrm{~km}$, the investment will not be extremely high: 16-23.5 million rubles. Such a short insertion expands the route network by $52 \mathrm{~km}$, i.e. doubles the total length of the trolleybus routes (Table 4). As result, it is possible to establish 4 new routes, each with the peak volume exceeding 1,000 passengers per hour. The most effective route would be from the Sverdlovsky borough to the city center because the expected volume is 2,000 passengers per hour (Figure 3 and 4).

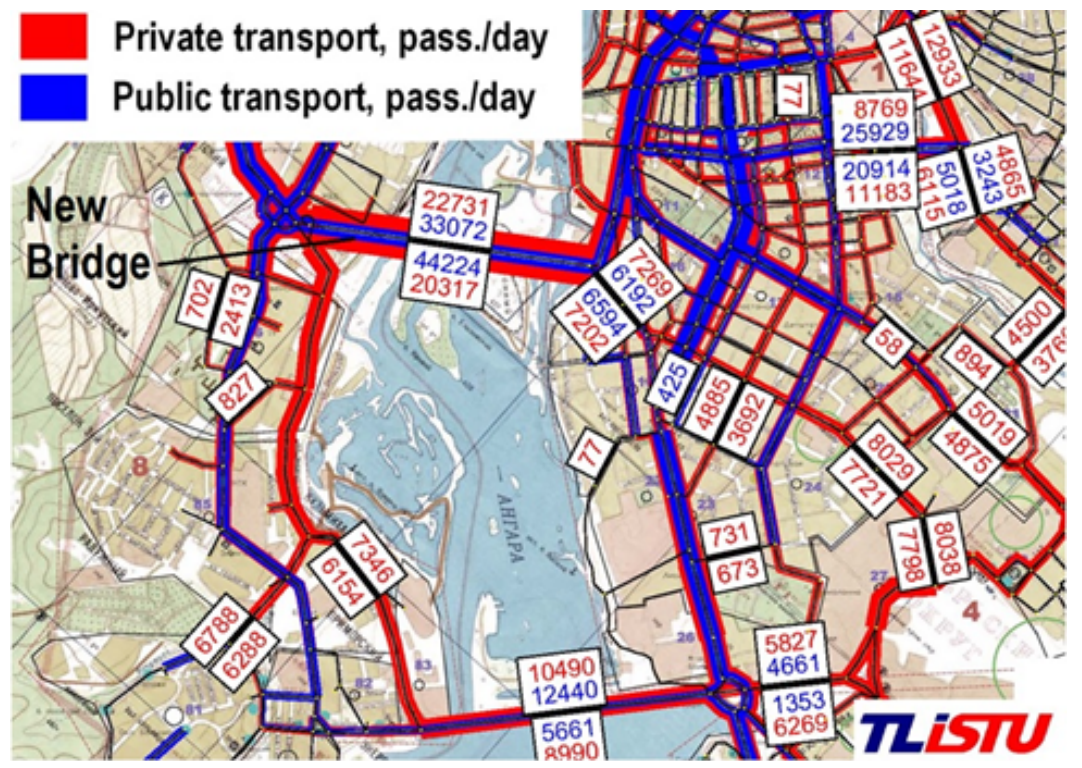

Figure 3: Daily passenger volumes (two modes: public transport and private cars) from Sverdlovskiy Borough to the city center and to Oktyabrskiy Borough in 2020. 


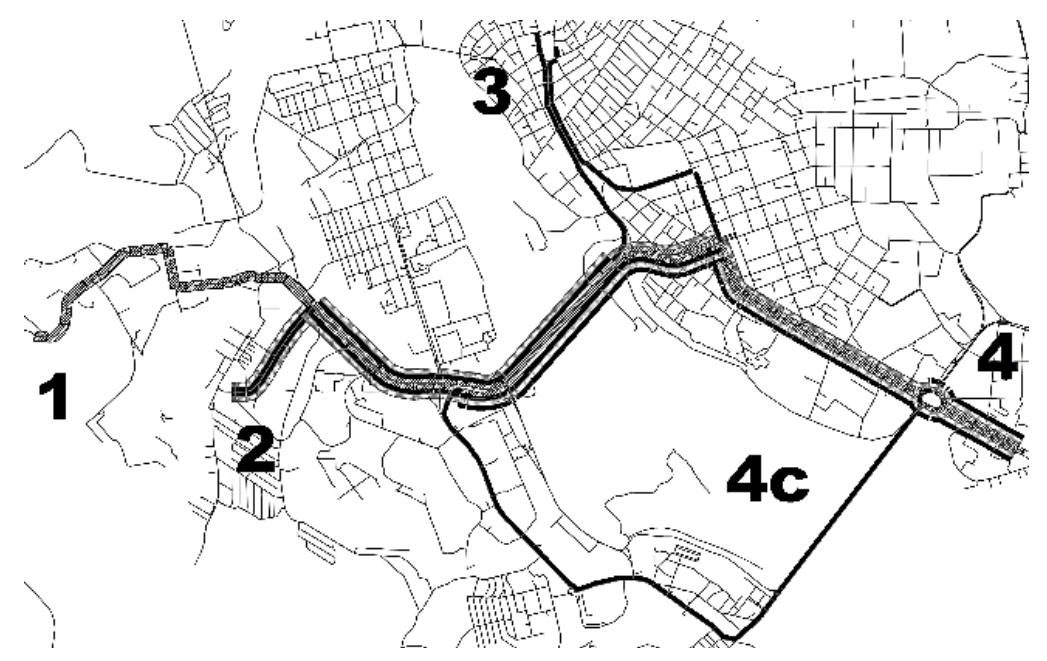

Figure 4: $\quad$ New trolleybus routes: $1-4 ; 2-4 ; 2-3 ; 4 \mathrm{c}$ (circular route).

Table 4: Length of new trolleybus routes.

\begin{tabular}{|l|l|l|l|l|}
\hline Route & $1-4$ & $2-4$ & $2-3$ & $4 \mathrm{c}$ \\
\hline Route length, $\mathrm{km}^{*}$ & 13,53 & 10,93 & 10,37 & 17,09 \\
\hline
\end{tabular}

*Note: Route length is the length of route in one direction.

In accordance with calculations, the number of trolleybuses should be increased by 30 vehicles. Modelling of the passenger flows distribution showed that suggested solution would increase trolleybus trips by $20-25 \%$ and would improve the economy of Irkutsk municipal electric transport.

\section{Conclusion}

The results of transportation demand estimation and passenger flows distribution forecasts convincingly prove the effectiveness of the proposed new development of trolleybus routes network. The length of the new additional trolleybus facility is only $3.35 \mathrm{~km}$, but short insertion expands the route network by $52 \mathrm{~km}$ and at least trolleybus passenger flows will be increased by $20-25 \%$.

The highway model presented in this paper has several drawbacks. Primarily in the further development of the scenario comparative analysis we must take into account the transport delays at intersections, which we can estimate using microsimulation. This addition will allow the production of a more accurate assessment of transport energy consumption.

It is also an interesting idea to extend the model to the agglomeration scope in order to check the effect of regional commuting on Irkutsk's passenger and transport flows. 
660 Energy Production and Management in the 21st Century, Vol. 1

\section{References}

[1] http://esco-ecosys.narod.ru/2012_1/art97.htm

[2] http://www.uitp.org//eupolicy/positions/2006/03/Climate_Change_EN.pdf

[3] www.unep.org/resourceefficiency

[4] Magaril, E., Improving the efficiency and environmental safety of gasoline engine operation. Proc. of 19th Int. Conf. on Urban Transport and the Environment, eds. C.A. Brebbia and J.W.S. Longhurst, WIT Press: Southampton, pp. 437-445, 2013.

[5] http://www.baltfriends.ru/sites/default/files/Transport\&env2.pdf

[6] http://irkipedia.ru/content/elektroenergetika_v_irkutsoy_oblasti_vinokurov_ ma_suhodolov_ap_ekonomika_irkutskoy_oblasti 